\title{
JUDICIALIZAÇÃO DE POLÍTICAS PÚBLICAS E O AJUSTAMENTO DAS NORMAS PROCESSUAIS CIVIS ÀS DEMANDAS INDIVIDUAIS DE SEGURIDADE SOCIAL
}

\section{JUDICIALIZATION OF PUBLIC POLICIES AND THE ADJUSTMENT OF CIVIL PROCEDURAL NORMS TO THE INDIVIDUAL DEMANDS OF SOCIAL SECURITY}

JOSÉ ANTONIO SAVARIS ${ }^{1}$

\begin{abstract}
RESUMO: O presente trabalho objetiva reafirmar as bases de proposta dogmática para o ajustamento de institutos e categorias do processo comum para as ações individuais em que se busca a proteção de direitos de seguridade social. Aponta o caráter multifacetário do tema da judicialização de políticas públicas, destacando a falta de atenção acadêmica às exigências do direito fundamental à tutela jurisdicional adequada em tema de direitos sociais. Valendo-se do método indutivo, articula dois níveis de judicialização, tendo como critério o objeto do provimento jurisdicional. Identifica que a judicialização de políticas públicas, em qualquer de seus níveis, pode ocorrer também mediante ações individuais, disciplinadas pelo processo civil comum. Demonstra a inadequação de algumas normas do processo civil para a proteção dos direitos de seguridade social, o que ilude o direito fundamental à adequada prestação jurisdicional. A partir dessas bases, o artigo expressa a necessidade de um teste de idoneidade das normas processuais para sua aplicação nas demandas de seguridade social, concluindo que a construção de uma nova conformação dos institutos e categorias processuais corresponde a um trabalho da dogmática e igualmente do juiz em uma situação concreta.
\end{abstract}

Palavras-Chave: Judicialização; Políticas Públicas; Direito Fundamentais; Seguridade Social; Tutela Jurisdicional.

\footnotetext{
${ }^{1}$ Doutor em Direito (USP). Mestre em Direito Econômico e Social (PUC-PR). Docente Permanente do Programa de Pós-Graduação Stricto Sensu da UNIVALI. Juiz Federal.. Contato: jasavaris@gmail.com.
} 
ABSTRACT: The present paper aims to reaffirm the bases of dogmatic proposal for the adjustment of institutes and categories of the common process for the individual actions in which the protection of social security rights is sought. It points out the multifaceted nature of the issue of the judicialization of public policies, highlighting the lack of academic attention to the requirements of the fundamental right to adequate judicial protection in the area of social rights. Taking advantage of the inductive method, it articulates two levels of judicialization, having as criterion the object of the judicial jurisdiction. It identifies that the judicialization of public policies, at any of its levels, can also occur through individual actions, disciplined by the common civil process. It demonstrates the inadequacy of some rules of civil procedure for the protection of social security rights, which eludes the fundamental right to adequate judicial performance. From these bases, the article expresses the need for a test of suitability of the procedural norms for its application in social security demands, concluding that the construction of a new conformation of institutes and procedural categories corresponds to a work of dogmatics and also of the judge in a concrete situation.

KeYwords: Judicialization; Public Policies; Fundamental Rights; Social Security; Jurisdictional Protection.

\section{INTRODUÇÃO}

O tema do controle jurisdicional das políticas públicas ${ }^{2}$ desafia estudos acadêmicos desde as mais variadas óticas, a começar pelo exame da própria sindicabilidade dos direitos sociais e do papel do Judiciário em sua concretização, de acordo com a dogmática constitucional da efetividade e da eficácia vinculante dos direitos fundamentais.

\footnotetext{
2 Em conhecido texto voltado eminentemente à conceituação jurídico-formal aplicável ao trabalho com políticas públicas, na perspectiva da funcionalidade do direito, assim entendidas as condições de atuação dos vários agentes, públicos e privados, envolvidos na concretização dos direitos sociais, Bucci $(2019$, p. 36) define política pública como "o programa de ação governamental que resulta de um processo ou conjunto de processos juridicamente regulados - processo eleitoral, processo de planejamento, processo de governo, processo orçamentário, processo legislativo, processo administrativo, processo judicial - visando coordenar os meios à disposição do Estado e as atividades privadas, para a realização de objetivos socialmente relevantes e politicamente determinados. Como tipo ideal, a política pública deve visar a realização de objetivos definidos, expressando a seleção de prioridades, a reserva de meios necessários à sua consecução e o intervalo de tempo em que se espera o atingimento dos resultados".
} 
Essas questões se relacionam à análise dos limites constitucionais do Poder Judiciário, desde uma perspectiva da separação e independência dos Poderes da República, do fenômeno do ativismo judicial (KMIEC, 2004; RAMOS, 2015; VALLE, 2009; TEIXEIRA, 2012; CAMPOS, 2015), e de como se materializa a judicialização de direitos humanos e fundamentais no direito pátrio e no contexto da justiça internacional.

É também indispensável a investigação do debate contemporâneo, no seio da teoria constitucional, relativo à justificação normativa do controle de constitucionalidade e das categorias político-jurídicas que lhe são pertinentes, como judicial review, jurisdição constitucional e democracia, sem que se subestimem as contribuições desde o terreno das teorias dos diálogos institucionais ${ }^{3}$.

Por outro lado, a tensão que se percebe entre as exigências de proteção suficiente dos direitos fundamentais e do mínimo existencial, de uma parte, e as implicações orçamentárias e a chamada reserva do possível, de outra parte, abrem largo campo para pesquisas, ainda não adequadamente coberto.

Desde a perspectiva da metodologia judicial, ainda são poucos os estudos dedicados a analisar criticamente o modo de ser do processo de tomada de decisões pela cúpula do Poder Judiciário, em tema de direitos sociais. Quando se tem em mira o exame crítico da racionalidade das decisões judiciais mais importantes em tema de direitos sociais, impressiona o jogo da argumentação jurídica e o grau de pragmatismo e de consequencialismo econômico de extração utilitarista nelas encontrado.

Mesmo que tantos aspectos dessa temática ainda demandem um olhar acadêmico mais próximo, talvez a matéria relativa à necessidade da adequação de garantias judiciais para a determinação dos direitos fundamentais de seguridade social, objeto do presente artigo, seja a mais precisada, destacadamente no contexto em que o problema dos direitos não é tanto o de justificá-los, mas o de protegê-los (BOBBIO, 1993).

É como se a adequação das garantias judiciais não constituísse parte do leque de problemas de natureza constitucional, administrativa ou processual relacionados ao grande tema da judicialização das políticas públicas e isso é ainda menos considerado quando a proteção do bem jurídico é buscada mediante ações individuais.

É insuficiente, porém, reconhecer-se a justiciabilidade dos direitos fundamentais sociais que não são objeto de regulamentação pelas instâncias políticas. Algumas condições mínimas são exigidas para a efetiva justiciabilidade de qualquer direito, dentre as quais a existência de ações e remédios judiciais

${ }^{3}$ Parece ser ainda um tema carente da devida consideração o da complementariedade entre as perspectivas do diálogo e da primazia institucional como fator de legitimação democrática da revisão judicial. Merece destaque, neste sentido, a proposição de que a interação deliberativa é condição de legitimidade da judicial review e apresenta maior probabilidade de alcançar boas respostas nos dilemas constitucionais ao longo do tempo (HÜBNER, 2011). 
adequados ao tipo de violação de que se trate (ABRAMOVICH; COURTIS, 2006, p. 80).

É pouco assegurar-se o acesso formal ao Poder Judiciário para a tutela contra violação ou ameça a direito, pois o princípio da proteção judicial, insculpido no art. 5, XXXV, da Constituição da República, ao expressar que "a lei não excluirá da apreciação do Poder Judiciário lesão ou ameaça a direito", consagra o direito fundamental a uma tutela jurisdicional efetiva e adequada.

É necessário, com efeito, que as pessoas possam manejar um "recurso efetivo" contra atos ou omissões que violem seus direitos fundamentais reconhecidos pela Constituição ou pela lei $i^{4}$. Mais especificamente, "O direito de ação tem como corolário o direito às técnicas processuais adequadas à tutela das várias necessidades do direito material e da realidade social" (MARINONI; ARENHART; MITIDIERO, 2016, p. 141).

O direito fundamental ao processo justo ou à tutela jurisdicional adequada, em tema dos direitos fundamentais sociais, enfrenta desafios de distintas ordens, mesmo porque a judicialização de políticas públicas é, em si, um fenômeno multiforme. E em função das diversas maneiras de lesão aos direitos sociais, não há uma única via jurisdicional, mas uma multiplicidade de vias para fazê-los efetivos (ABRAMOVICH; COURTIS, 2006, p. 82).

Se a judicialização se expressa em um contexto de demandas individuais, tornase fundamental a análise crítica da adequação das formas, conceitos, institutos e categorias do processo civil comum, idealizados para solução de conflitos entre particulares e para a proteção de direitos patrimoniais, quando destinados a regulamentar o processo dos direitos de seguridade social.

O presente estudo compartilha da compreensão de que é necessário avaliar-se a adequação do Código de Processo Civil para a tutela dos direitos e se corrigir judicialmente a legislação, com o objetivo de se proteger adequadamente os direitos fundamentais processuais (MARINONI; ARENHART; MITIDIERO, 2016, p. 71).

Em face disso, valendo-se do método indutivo, propõe-se, preliminarmente, uma classificação de níveis de judicialização de políticas públicas, de acordo com o objeto da jurisdição, com o objetivo de melhor pontuar que a necessidade de diretrizes processuais específicas para as ações individuais de seguridade social consubstancia proposição normativa inserida na temática da judicialização de políticas públicas e deve ser percebida como exigência do direito fundamental à tutela jurisdicional adequada.

Na sequência, procura-se demonstrar o descabimento de alguns relevantes institutos, categorias e técnicas do processo civil comum às ações individuais de

${ }^{4}$ Art. 25, 1, da Convenção Americana de Direitos Humanos (Pacto de San José da Costa Rica, de 22.11.1969). Ratificação: 25.09.1992; Promulgação no Brasil: Decreto 678, de 06.11.1992. 
seguridade social, pois sua aplicação acarreta importantes obstáculos para a judicialização de políticas públicas em nosso País 5 .

A partir disso, reafirma-se específica diretriz normativa para as ações de seguridade social a partir de uma postura dogmática atenta às particularidades do direito material, das pessoas envolvidas nesses processos, e das exigências constitucionais de tutela efetiva desse direito fundamental: o teste da idoneidade da norma processual civil - e as exigências de sua nova conformação - para as ações de seguridade social.

\section{DOIS NÍVEIS DE JUDICIALIZAÇÃO DE POLÍTICAS PÚBLICAS. O OBJETO DA JURISDIÇÃO COMO CRITÉRIO}

Qualquer discussão relativa ao controle jurisdicional de políticas públicas pressupõe, como imperativo lógico, a análise do que se pode considerar como políticas públicas ${ }^{6}$.

Se a compreensão é a de que políticas públicas consubstanciam o principal mecanismo de ação estatal com vistas à realização dos direitos sociais, econômicos e culturais (BREUS, 2007, p. 204), ou programas e ações do Poder Público destinados a atingir os objetivos fundamentais do Estado (GRINOVER, 2008, p. 26; STAFFEN, 2015), é correto afirmar que a temática da judicialização das políticas públicas corresponde a um problema político-jurídico, com todas as implicações da intervenção judicial nas escolhas políticas, econômicas e sociais realizadas pelos demais Poderes.

Sem embargo, a intervenção judicial pode ocorrer apenas e tão somente na implementação ou execução final de política pública, de modo que não se encontraria em discussão, em linha de princípio, as opções políticas do Parlamento ou da Administração Pública.

É importante essa referência à dupla-face da judicialização, que tem como critério o objeto da tutela jurisdicional - e, por conseguinte, os meios para sua prestação - para precisarmos que o âmbito da jurisdição que constitui objeto do

\footnotetext{
${ }^{5} \mathrm{~A}$ inadequação do processo civil para direitos sociais apresenta causas históricas. No modelo do Estado Liberal e de Direito, contexto em que idealizado o processo civil comum, a preocupação era fundamentalmente a de oferecer garantias apenas aos direitos individuais tradicionais, que consistem em liberdades - como a propriedade, liberdade e a segurança. De todo modo, mesmo no contexto do Estado Constitucional de Direito se percebe a inadequação de categorias processuais aos novos direitos, o que só faz transparecer a falta de sensibilidade do legislador para a necessária adequação do processo às particularidades do direito material social.

${ }^{6}$ Conforme aponta Appio (2005, p. 133), "essa indagação deveria se constituir no pórtico de qualquer debate jurídico sobre o tema, na medida em que a atividade judicial de revisão do conteúdo das políticas públicas deve ser estudada, com o objetivo de se evitar o transporte, puro e simples, das teorias que embasam a revisão judicial dos atos administrativos para o interior de um sistema político, o sistema Constitucional".
} 
presente estudo não é o da tutela por ações judiciais especiais, geralmente relacionadas à violação que afeta um grupo extenso de pessoas.

Antes, a preocupação que se materializa neste trabalho tem como foco a tutela jurisdicional em ações individuais, geralmente fundadas sobre bases legais (direitos regulamentados por lei) e que são disciplinadas pelas regras do Código de Processo Civil ou da lei dos juizados especiais federais. E nessa dimensão da judicialização, partindo-se do direito fundamental à tutela jurisdicional adequada, pretende-se firmar a premissa de que as técnicas do direito processual civil, se não forem idôneas para a assegurar a devida judicialização dos direitos sociais de seguridade social, devem ser ajustadas, flexibilizadas, elastecidas ou relativizadas.

1. A judicialização de politicas públicas de primeiro nível. A discricionariedade no jogo político-jurídico

O primeiro nível de judicialização de políticas públicas pode ser caracterizado como judicialização de políticas públicas stricto sensu, pois nela se discute o mérito da política pública abrangentemente considerada, a discricionariedade parlamentar ou administrativa ou as escolhas políticas de alocação de recursos públicos para atendimento de políticas econômicas ou sociais mais diversas. Carrega, por isso, todo o conjunto de problemáticas específicas que se relacionam à efetivação judicial de direitos fundamentais sociais quando inexistente a necessária regulamentação legislativa ${ }^{7}$.

Nesse paradigma de judicialização, o direito a prestação que se pretende reconhecer judicialmente não se encontra no raio de política pública efetivamente implementada pelas instâncias políticas. Antes, o que se tem é a identificação de omissão, total ou parcial, administrativa ou legislativa, para a concretização de normas que asseguram direitos sociais de natureza prestacional e a definição judicial do nível de eficácia dessas normas constitucionais.

A proteção judicial dos direitos sociais apresenta-se aqui como uma "profunda revisão da institucionalidade das políticas, em seu modo de organização e implementação, e no tipo de relação que se estabelece com os beneficiários" (ABRAMOVICH, 2009, p. 10).

Esse nível de judicialização chega a suscitar críticas por consubstanciar uma forma de ativismo judiciário, pois o órgão jurisdicional estaria a determinar a implementação efetiva de direito fundamental, sem considerar a índole programática da norma constitucional ou a necessidade de "providências integrativas de amplo espectro (que vão da formulação de políticas públicas adequadas à sua cabal execução, abrangente de medidas legislativas,

\footnotetext{
${ }^{7} \mathrm{O}$ pano de fundo deste nível de judicialização conecta temas como o exercício atípico da função legislativa positiva pelo Poder Judiciário, o princípio da separação dos poderes, o controle jurisdicional da discricionariedade em favor do poder Legislativo ou da Administração, incluindose alocações orçamentárias etc.
} 
administrativas - normativas e não normativas - e orçamentárias)" (RAMOS, 2015, p. 185$)^{8}$.

$\mathrm{Na}$ judicialização de políticas públicas stricto sensu inexiste, portanto, regulamentação do direito ou definição dos critérios de elegibilidade, de modo que o bem jurídico não se encontra, em tese, disponibilizado por lei aos particulares. Não se pode falar, portanto, em cumprimento dos requisitos legais pelo suposto titular do direito'.

Segue daí que, nesse primeiro nível de judicialização, o instrumento processual em que se busca determinada proteção social pode fundar-se na ausência (omissão total) ou na inadequação (omissão parcial) de política pública. Nessa perspectiva, em linha de princípio, a intervenção judicial faz frente a omissões (total ou parcial) inconstitucionais que se imputam aos Poderes Públicos quanto à formulação e implementação das políticas públicas necessárias para a satisfação dos direitos fundamentais sociais.

O grau de intervenção judicial nas políticas é, nesse modelo, mais intenso, geralmente materializado no bojo de mecanismos processuais próprios para emissão de provimentos judiciais com alcance mais genérico ${ }^{10}$. Com efeito, a judicialização de primeiro nível é geralmente realizada em sede de ações coletivas ou outros instrumentos processuais especiais, pelos quais se busca tutelar direitos difusos ou individuais homogêneos que são lesados por omissões inconstitucionais dos Poderes Públicos ${ }^{11}$.

Se o direito social é violado, em tese, porque não se encontra no raio de políticas públicas ou porque inexiste norma regulamentadora a viabilizar seu exercício, a busca da tutela jurisdicional, em situações concretas, pode se realizar pelo mandado de injunção ou pelos instrumentos processuais construídos para a tutela dos direitos difusos, coletivos e individuais homogêneos, como a ação civil pública. Também o controle do cumprimento e da realização das políticas públicas pode ocorrer pelas ações constitucionais de controle concentrado de constitucionalidade, como a ação direta de inconstitucionalidade por omissão e a arguição por descumprimento de preceito fundamental, sendo amplo o rol de legitimados para a sua propositura.

\footnotetext{
${ }^{8}$ Para este autor, seria conceituado o ativismo judicial como "o exercício da função jurisdicional para além dos limites impostos pelo próprio ordenamento que incumbe, institucionalmente, ao Poder Judiciário fazer atuar", podendo representar a invasão, pelo Poder Judiciário, do espaço de conformação normativa do Poder Legislativo (RAMOS, 2010, p. 129).

${ }^{9}$ Estar-se-ia em discussão, por exemplo, a implementação de direitos sociais veiculados por norma de eficácia limitada.

${ }^{10}$ Em sua tarefa de caracterização dogmática do ativismo judicial, Elival da Silva Ramos (2015, p. 113) realiza uma espécie de gradação do controle judiciário dos atos do Poder Público em matéria constitucional, com o objetivo de se avaliar o caráter ativista ou não de determinada decisão judicial.

11 De fato, "As ações coletivas, como mecanismo de processamento de demandas coletivas e massificadas, a partir das class actions norte-americanas, são o meio, por excelência, de solução de conflitos envolvendo os direitos sistematizados em políticas públicas" (BUCCI, 2006, p. 31).
} 
Constituem relevantes temas, nesse contexto, (i) a catalogação das especiais ações de índole constitucional para a tutela dos direitos subjetivos, (ii) os mecanismos técnico-processuais das ações coletivas e a sua idoneidade para a tutela dos direitos fundamentais sociais, e (iii) seus efeitos, em termos práticos, para a coletividade interessada.

Por outro lado, mesmo para o que se pode considerar como uma típica intervenção judicial em políticas públicas, em que se alcança a análise da obrigação de implementação de determinados direitos sociais, o cidadão pode se valer de ações individuais ${ }^{12}$.

De todo modo, essa espécie de judicialização, fundamentalmente relacionada ao controle jurisdicional da discricionariedade dos outros Poderes quanto às suas ações ou omissões relativas a políticas públicas, enseja problemas menos relacionados com a adequação dos procedimentos e mais conectados com o problema da eficácia e efetividade das normas de direitos sociais e com as implicações relativas à exigibilidade dos direitos sociais como direitos a prestações.

Ainda que as decisões que definem políticas públicas sejam marcadas pela indivisibilidade, é plenamente possível o manejo de ação individual para a implementação ou para a correção de uma política pública que tenha efeitos coletivos (GRINOVER, 2008, p. 25), sendo muito comum, ademais, o acesso à justiça para obtenção de direito social, em uma situação concreta, fundado no texto constitucional, por meio de ações estritamente individuais, isto é, aquelas cujo resultado do processo aproveitará apenas ao seu autor ${ }^{13}$.

\begin{abstract}
2. A judicialização de politicas públicas de segundo nivel. A legalidade no jogo administrativo

O segundo nível de judicialização pode ser caracterizado como uma judicialização de políticas públicas lato sensu. Nesse paradigma de judicialização, o direito social reivindicado é objeto de política pública que se encontra implementada pelas instâncias políticas competentes. O sistema normativo, nesse contexto, já define os critérios de elegibilidade, de modo que o bem jurídico se encontra, em tese, disponibilizado para os particulares que atendam os requisitos legais.
\end{abstract}

${ }^{12}$ De fato, não se pode perder de vista "que o sujeito inserido na coletividade carente de certa política pública poderá requerer a tutela da sua parcela subjetiva daquele direito coletivo, por intermédio de uma demanda individual, que trará somente a ele a proteção requerida" (ZUFELATO, 2011, p. 327).

${ }^{13}$ Nesse sentido: "Essas ações estritamente individuais têm sido utilizadas com frequência na prática forense, sobretudo em questões envolvendo direito à saúde, como as demandas que visam à obtenção de determinado medicamento às custas do Estado ou a realização de exames ou procedimento cirúrgico não disponibilizado pelo SUS" (ZUFELATO, 2011, p. 328). 
Sem embargo, o direito não é satisfeito pelos Poderes Públicos, ou porque se entende não haver comprovação de atendimento dos requisitos legais pelo interessado, ou pela ausência de condições fáticas para adimplir a obrigação jurídica.

Segue daí que, nesse nível de judicialização, a ação em que se busca determinada proteção social pode fundar-se em três linhas argumentativas que não são auto excludentes: (i) a efetiva existência de fatos não reconhecidos pela Administração Pública e que implicam o cumprimento dos requisitos legais: (ii) a ilegalidade de exigência administrativa amparada em ato normativo infralegal que extrapolaria o poder regulamentar, por veicular condições ou requisitos não previstos em lei no sentido formal e material; (iii) a inconstitucionalidade de critério ou elemento constitutivo do critério de elegibilidade estabelecido em lei, por incompatibilidade formal ou material com norma constitucional.

Nessas três modalidades argumentativas de demanda judicial de proteção social, não se discute a política pública abrangentemente considerada, mas aspecto pontual de sua implementação que consubstancia errônea interpretação administrativa de fatos ou normas, nos dois primeiros casos, ou inconstitucionalidade do critério adotado pelo legislador, no caso derradeiro.

Nessa perspectiva, em linha de princípio, não há omissão imputável aos Poderes Públicos quanto à formulação ou implementação das políticas públicas necessárias para a satisfação dos direitos fundamentais sociais. O que se tem é a violação de direito, em tese, por não cumprimento das regras, por parte da Administração, seja porque avaliou mal os fatos, seja porque editou norma mais restritiva que extrapola a lei, seja porque se amparou em norma legal que é incompatível com a Constituição.

Nesse segundo nível de judicialização de políticas públicas, busca-se predominantemente assegurar a fiel realização de política pública já definida por lei e que já corresponde a medidas concretas, porque plenamente regulamentados os direitos sociais.

Não se encontra em avaliação, nesse cenário, o exercício da discricionariedade administrativa ou suas escolhas relativas à alocação de recursos públicos e prioridades econômicas, políticas ou sociais.

O grau de intervenção judicial nas políticas públicas é, aqui, mínimo, geralmente materializado em determinado caso concreto como resposta a um agir administrativo que, em tese, se encontra em desconformidade com a própria política pública definida pelos poderes democraticamente eleitos.

E nem mesmo representa uma judicialização de políticas públicas em sentido estrito a excepcional (i) flexibilização de requisito legal, mediante adoção de diretrizes hermenêuticas que têm como comum ponto de partida a dissociação ontológica entre texto e norma ou (ii) o afastamento de critério de elegibilidade pela via do controle difuso de constitucionalidade. 
Com efeito, antes de uma intervenção nas escolhas políticas, o que se tem nesses casos predominantemente é a interpretação das normas jurídicas que integram as políticas públicas e que concretizam os direitos fundamentais. Trata-se, com efeito, de interpretação do conjunto normativo e de sua aplicação, à luz de diretrizes hermenêuticas dos direitos fundamentais e das exigências metodológicas de constituição equitativa da norma para o caso concreto, o que implica ajustamento das normas, gerais e abstratas, às particularidades do problema jurídico em concreto.

Desde que a violação a direito social ocorre mediante descumprimento administrativo das normas de seguridade social em desfavor de sujeito determinado, a judicialização se expressará, via de regra, por ações estritamente individuais que, em essência, buscam o afastamento de ato concreto dos Poderes Públicos responsáveis pela execução das políticas públicas ${ }^{14}$.

\section{DESCONCERTOS DE CATEGORIAS DO PROCESSO CIVIL COMUM NAS DEMANDAS INDIVIDUAIS DE SEGURIDADE SOCIAL}

Como se viu nas seções anteriores, a judicialização de políticas públicas, em qualquer de seus níveis, pode se realizar por demandas estritamente individuais.

A proteção judicial do direito pressupõe, nesses casos, o manejo de instrumentos processuais que são orientados pelas normas do processo civil comum, merecendo análise, desde a perspectiva da garantia dos direitos, a adequação dos procedimentos às particularidades do direito material, enquanto pressuposto do direito fundamental à tutela jurisdicional adequada.

Uma questão particular que se apresenta com a justiciabilidade dos direitos sociais deriva do fato de que grande parte dos instrumentos processuais foram desenhados para conflitos entre indivíduos privados. Essa circunstância pode dificultar, em alguma medida, a adequada proteção judicial dos direitos sociais, "porque em muitos casos esse direitos têm dimensões e projeções coletivas, tema que constitui uma relativa novidade em matéria de procedimentos judiciais" (ABRAMOVICH; COURTIS, 2006, p. 81).

Com efeito, o processo civil é fortemente influenciado pela necessidade de proteção à propriedade, à liberdade e à segurança, direitos próprios do Estado Liberal. É pensado predominantemente para resolver problemas privados, de cunho eminentemente patrimonial ${ }^{15}$.

14 A judicialização de segundo nível é geralmente realizada por meio de ações estritamente individuais, embora também o cenário seja marcado pelo manejo de ações coletivas que buscam afastar ilegalidades administrativas pontuais que são identificadas no estágio de implementação da política pública correlata.

${ }^{15}$ Mais particularmente: "No modelo antigo, a Constituição era compreendida, essencialmente, como um documento político, cujas normas não eram aplicáveis diretamente, ficando na dependência de desenvolvimento pelo legislador ou pelo administrador. Tampouco existia o controle de 
Como a "preocupação do direito se centrava na defesa da liberdade do cidadão diante do Estado, a uniformidade procedimental e as formas possuíam grande importância para o demandado", o que se tinha era um "um processo civil insensível" à tutela de novas realidades (MARINONI; ARENHART; MITIDIERO, 2016, p. 31), como as especificidades dos direitos fundamentais sociais e dos destinatários das políticas públicas que lhes correspondem.

Esses problemas continuam ainda no contexto do Estado Constitucional de Direito. Desde a inadequação do instituto da coisa julgada, considerada como a autoridade que torna imutável e indiscutível a decisão de mérito não mais sujeita a recurso (CPC, art. 502), vis à vis a não-preclusão dos direitos fundamentais de seguridade social, enquanto elementos constitutivos do direito à vida e intimamente conectados com o mínimo existencial e a dignidade da pessoa humana.

Também a rigidez dos princípios dispositivo (CPC, art. 2º) e da correlação da sentença ao pedido (CPC, art. 492) é desajustada aos processos de seguridade social. Importa reconhecer que a busca de um fazer estatal para a concretização de direito fundamental deve ser compreendida em um sentido amplo, considerandose as consequências das omissões estatais na análise da posição jurídica mais favorável na via administrativa, a eficácia vinculante dos direitos fundamentais, a assimetria de forças entre as partes e mesmo a vinculação dos Poderes Públicos ao princípio da legalidade ${ }^{16}$.

Igualmente pode se apontar o descabimento, aos processos da seguridade social, da técnica processual da tutela de urgência de natureza antecipada, na parte que apresenta como pressuposto negativo o perigo de irreversibilidade dos efeitos da decisão (CPC, art. 300, § 3o). Isso porque nas lides de seguridade social inegavelmente se encontra presente o perigo de irreversibilidade dos efeitos da decisão provisória, porque a parte é economicamente hipossuficiente e os valores, de natureza alimentar, são consumidos para sua manutenção. A exigência desse pressuposto negativo implicaria, em última análise, denegação de justiça, porque inviabilizaria a tutela de urgência nas ações de seguridade social ${ }^{17}$.

constitucionalidade das leis pelo Judiciário - ou, onde existia, era tímido e pouco relevante. Nesse ambiente, vigorava a centralidade da lei e a supremacia do parlamento. No Estado constitucional de direito, a Constituição passa a valer como norma jurídica. A partir daí, ela não apenas disciplina o modo de produção das leis e atos normativos, como estabelece determinados limites para o seu conteúdo, além de impor deveres de atuação ao Estado. Nesse novo modelo, vigora a centralidade da Constituição e a supremacia judicial, como tal entendida a primazia de um tribunal constitucional ou suprema corte na interpretação final e vinculante das normas constitucionais" (BARROSO, 2015).

${ }^{16}$ Sobre esse tema específico, veja-se Savaris (2012).

${ }^{17}$ A tutela de urgência em matéria de seguridade social é indispensável para a jurisdição assegurar a adequada proteção desses direitos fundamentais, pois constitui técnica processual idônea para evitar o prolongamento da situação antijurídica que priva o titular do direito violado de recursos materiais necessários à sua subsistência. Com efeito, "Como técnica processual inerente à conformação do processo justo e, muito especialmente, do direito à tutela jurisdicional adequada e 
Por outro lado, a restituição ao status quo ante é inapropriada nos processos de seguridade social, pois a reversibilidade dos efeitos fáticos da decisão provisória pode implicar, por exemplo, a necessidade de devolução de valores previdenciários ou assistenciais de natureza alimentar, que se presumem consumidos, ou o dever de indenizar pela "indevida" utilização de fármacos ${ }^{18}$.

Como se pode observar, os direitos de seguridade social não podem ser tutelados de maneira adequada em um contexto de rigidez de conceitos processuais, sendo vital para as pessoas o manejo de "procedimentos adequados às necessidades das diferentes situações de direito substancial" (MARINONI, et al, 2016, p. 31).

É necessária, portanto, a elaboração de teste de idoneidade dos institutos, técnicas e categorias processuais, os quais, mercê da eficácia normativa do direito fundamental à tutela jurisdicional adequada, devem ser conciliados às particularidades dos direitos fundamentais de seguridade social e de seus destinatários, especialmente quando os bens jurídicos são tutelados em um contexto processual tradicional e não por ações especiais.

\section{TESTE DE IDONEIDADE DAS NORMAS PROCESSUAIS PARA JUDICIALIZAÇÃO DE POLÍTICAS PÚBLICAS}

A existência de ações e técnicas processuais para a proteção dos direitos fundamentais sociais é pressuposto para a tutela desses direitos. Não se trata de garantir formalmente o acesso à justiça, mas de se disponibilizar mecanismos processuais hábeis a efetivamente proteger os direitos sociais contra as mais diversas formas de violação.

Embora as ações especiais e coletivas constituam meios processuais apropriados para a judicialização de políticas públicas, porque idealizadas para a tutela dos direitos difusos, coletivos e individuais homogêneos, elas não exaurem as possibilidades de acesso à justiça para a obtenção de direitos sociais como direito

efetiva, a técnica antecipatória é essencial para realização ou acautelamento dos direitos" (SARLET et al., 2016, p. 823).

18 A irreversibilidade e definitividade dos efeitos fáticos das tutelas provisórias em matéria previdenciária foi objeto de nossa proposição e se relaciona com o princípio da irrepetibilidade dos valores alimentares recebidos de boa-fé: "Por um lado, os efeitos fáticos da decisão que concede tutela provisória em matéria previdenciária são irreversíveis porque o retorno ao estado de coisas anterior não é materialmente possível, por força da presunção do consumo da verba de natureza alimentar e da ausência de condições reais do autor para repetir. Por outro lado, esses efeitos fáticos são irreversíveis porque o restabelecimento da situação anterior não é juridicamente devido, pois a exigência de devolução das prestações previdenciárias de natureza alimentar que correspondem a direito fundamental de pessoa vulnerável, além de configurar imposição desproporcional, encontraria óbice no princípio da dignidade da pessoa humana e no direito constitucional ao mínimo existencial, constituindo, ademais, o pretenso dever retroativo, autêntica armadilha processual e odioso retrocesso social" (SAVARIS, 2019, p. 528). 
a prestações. É também cabível a propositura de ação individual para o aqui chamado controle de políticas públicas propriamente dito. Mais do que isso, as ações estritamente individuais são ainda o modo mais comum de tutela dos direitos em situações concretas, em manifestação do que foi anteriormente denominado judicialização de políticas públicas lato sensu.

As ações individuais são regidas pelas normas do processo civil comum e a sua aplicação acrítica pode implicar inadequação da tutela jurisdicional de controle de políticas públicas. Os institutos, técnicas e categorias processo civil comum podem ser insuficientes ou inadequadas à efetiva proteção dos direitos de seguridade social, porque historicamente presas aos valores das liberdades pessoais ou liberdades negativas, próprios do Estado Liberal.

$\mathrm{O}$ ajustamento das normas processuais civis às particularidades do direito material da seguridade social e de seus destinatários não é apenas necessário, mas possível; devido. A eficácia normativa do direito fundamental à tutela jurisdicional adequada impõe um teste de idoneidade das categorias do processo civil comum com vistas a uma eventual nova conformação, de modo a se assegurar a efetiva proteção dos direitos fundamentais sociais ${ }^{19}$.

É preciso reconhecer que o processo neutro em relação ao direito material "é incapaz de atender às necessidades de tutela reveladas pelos novos direitos e, assim, de viabilizar o cumprimento do dever estatal de tutela dos direitos, que constitui a essência do Estado contemporâneo" (MARINONI; ARENHART; MITIDIERO, 2016, p. 129).

Nesse contexto, a construção dogmática e judicial de técnicas processuais aderentes ao direito material torna-se indispensável à proteção do direito fundamental substancial e, igualmente, à proteção do direito fundamental processual de acesso à justiça.

Não é novidade que a mudança de paradigma em relação ao desenho e à teoria constitucionais, com a transição do Estado Legislativo de Direito para o Estado Constitucional de Direito, permitiu assegurar-se a eficácia jurídica e social das normas (regras e princípios) constitucionais ${ }^{20}$.

Mais do que proteger os cidadãos contra violações do direito expresso em leis, alcança maior importância o Poder Judiciário na tutela dos direitos fundamentais,

19 "O direito fundamental de ação é a linha que costura a relação entre as tutelas prometidas pelo direito material e as técnicas processuais. A falta de adequação entre as técnicas processuais e as tutelas dos direitos põe o direito fundamental da ação em perigo, pois coloca em risco a obtenção da tutela efetiva do direito mediante o exercício da ação" (MARINONI; ARENHART; MITIDIERO, 2016, p. 126).

${ }^{20}$ A alteração da concepção do que se tem por norma jurídica, no pós-Segunda Guerra Mundial, que passa a ser compreendida como gênero, de que são espécies regras e princípios, traz consigo a questão da normatividade dos princípios, seu alto grau de generalidade e a necessidade de sua concretização por via interpretativa, o que pavimenta a racionalidade jurídica do ativismo judicial: "decisões fundamentadas substancialmente em princípios, afastando ou negando a aplicabilidade de regras específicas para a fatispécie" (TEIXEIRA, 2012). 
valendo-se de metodologia judicial específica que permite, de um lado, compreender esses direitos fundamentais como hábeis a outorgar pretensões subjetivas, e de outro lado, interpretar as normas jurídicas desde a ótica da proteção e efetivação desses direitos de elevada dignidade.

A perspectiva assumida no presente texto se dá no sentido de que os direitos fundamentais, mercê da centralidade que ocupam no sistema normativo, devem ser objeto da mais efetiva proteção e realização. E essa tarefa se impõe não apenas aos Poderes democraticamente eleitos, mas igualmente ao Poder Judiciário, a quem incumbe zelar pelo respeito e pela efetivação da Lei Maior, seja por ação, seja por omissão dos órgãos, instituições e autoridades da República.

Por essa razão, não apenas é possível como necessário que o juiz proceda à filtragem das normas processuais civis, tornando-a compatível com as particularidades das lides de seguridade social, em que uma pessoa presumivelmente hipossuficiente em termos econômicos e informacionais busca, em face de entidade estatal, a realização de direito fundamental social intimamente ligado às exigências de mínimo existencial e de dignidade da pessoa humana.

É necessário anotar que as mais variadas controvérsias relacionadas ao tema da judicialização de políticas públicas tem como pano de fundo os limites de atuação do Poder Judiciário - ou os limites do que se convencionou chamar de ativismo judicial $^{21}$. Também aqui, perceba-se, a problemática concernente à atuação do juiz na tarefa de conciliação das normas processuais civis às demandas de seguridade social revela sua total pertinência ao grande tema da judicialização de políticas públicas, provocando reflexões quanto à hermenêutica dos direitos fundamentais e o papel do Poder Judiciário na sua efetiva proteção.

\section{CONCLUSÃO}

Ante a exigência de máxima concretização e efetiva proteção dos direitos fundamentais, a sua tutela jurisdicional oferece diversas problemáticas de natureza política, jurídica, social e econômica, porque colocam o Poder Judiciário na rota de interferência nos demais Poderes.

Conquanto a adequação dos mecanismos processuais seja exigência do direito fundamental à tutela jurisdicional adequada e garantia necessária para a efetiva

${ }^{21}$ A origem do termo "ativismo judicial" é atribuída ao historiador norte-americano Arthur Schlesinger Jr que, no artigo The Supreme Court: 1947, publicado na popular Revista Fortune, lançou análise crítica à orientação dos juízes da Suprema Corte dos EUA daquele ano, tendo alguns por ativistas ("Judicial Activists") e outros por autorrestritivos ("Champions of Self Restraint"), que mantinham fundamentalmente uma disputa intelectual quanto à função da Suprema Corte em uma democracia e, de modo particular, no sistema de governo estadunidense (KMIEC, 2004). O ativismo judicial estaria relacionado à substituição da vontade do legislador pela dos juízes, sob entendimento de que o Judiciário deve atuar ativamente na promoção das liberdades civis e dos direitos das minorias, dos destituídos e dos vulneráveis. Essa expansão do Poder Judiciário, evidentemente, jamais seguiu isenta de críticas. 
proteção judicial dos direitos fundamentais sociais, esse é uma tema ainda pouco explorado na temática de judicialização de políticas públicas.

No contexto do Estado Constitucional, a proteção dos direitos fundamentais se encontra no centro dos deveres estatais, evidenciando-se a necessidade de uma nova postura dogmática, orientada a analisar criticamente o sistema jurídico e a justificar a necessidade de adaptação de institutos ou técnicas processuais às características particulares dos direitos sociais de seguridade social e de seus destinatários.

Dada a força vinculante dos princípios constitucionais e dos direitos fundamentais, a função jurisdicional deve ser identificada fundamentalmente como modalidade de proteção jurídica assegurada pelo Estado à efetiva realização desses direitos de superior dignidade.

Se é correto afirmar que a judicialização de políticas públicas é geralmente associada ao manejo de ações constitucionais e outros meios processuais coletivos, também é certo reconhecer que as ações exclusivamente individuais constituem meio hábil de acesso à justiça, seja para revisão das políticas públicas abrangentemente consideradas (judicialização stricto sensu, conforme aqui proposto), seja para a revisão de ato administrativo (judicialização lato sensu, segundo o mesmo critério).

Todavia, o efetivo acesso à justiça para a proteção dos direitos sociais de seguridade social pressupõe uma análise crítica das formas processuais civis, demando uma filtragem quanto à sua adequação, desde a perspectiva do direito fundamental ao processo justo, tarefa de aprimoramento que inegavelmente é também confiada ao Poder Judiciário.

\section{REFERÊNCIAS}

ABRAMOVICH, Victor; COURTIS, Christian. El umbral de la ciudadanía: el significado de los derechos sociales en el Estado social constitucional. Buenos Aires: Del Puerto, 2006.

ABRAMOVICH, Victor. El rol de la justicia en la articulación de políticas y derechos sociales. In: ABRAMOVICH, Victor; PAUTASSI, Laura. La revisión judicial de las políticas sociales: estudio de casos. Buenos Aires: Del Puerto, 2009.

APPIO, Eduardo. Controle judicial das políticas públicas no Brasil. Curitiba: Juruá, 2005. 
BARROSO, Luis Roberto, A Razão Sem Voto: O Supremo Tribunal Federal e o Governo da Maioria. 2015. Disponível em:

$<$ http://dx.doi.org/10.2139/ssrn.2915571>. Acesso em: 16 dez. 2019.

BOBBIO, Norberto. A era dos direitos. 11 ed. Trad. Carlos Nelson Coutinho. São Paulo: Campus, 1993.

BREUS, Thiago Lima. Políticas públicas no Estado Constitucional: problemática da concretização dos direitos fundamentais pela Administração Pública brasileira contemporânea. Belo Horizonte: Fórum, 2007.

BUCCI, Maria Paula Dallari. O conceito de política pública em direito. In: BUCCI, Maria Paula Dallari (Org.). Políticas Públicas: reflexões sobre o conceito jurídico, São Paulo: Ed. Saraiva, 2006.

CAMPOS, Carlos Alexandre de Azevedo. Estado de coisas inconstitucional. Juspodivm, 2015.

GRINOVER. Ada Pellegrini. O controle das políticas públicas pelo Poder Judiciário. Revista de Processo, v. 164, 2008, p. 09-28.

HÜBNER Mendes, Conrado. Direitos Fundamentais, Separação de Poderes e Democracia. São Paulo: Saraiva, 2011.

KMIEC, Keenan D. The Origin and Current Meanings of 'Judicial Activism. California Law Review, v. 92, 2004, p. 1441-77.

MARINONI, Luiz Guilherme; ARENHART, Sérgio Cruz; MITIDIERO, Daniel. O Novo Processo Civil. 2 ed. São Paulo: Revista dos Tribunais, 2016.

SARLET, Ingo Wolfgang; MARINONI, Luiz Guilherme e MITIDIERO, Daniel. Curso de Direito Constitucional. 5 ed. São Paulo, 2016.

SAVARIS, José Antonio. Coisa julgada previdenciária como concretização do direito constitucional a um processo justo. Revista Brasileira de Direito Previdenciário, v. 1, p. 65-86, 2011.

SAVARIS, José Antonio. Princípio da primazia do acertamento judicial da relação jurídica de proteção social. Revista NEJ Eletrônica, v. 17, n. 3, 2012, p. 419-437. 
SAVARIS, José Antonio. Direito Processual Previdenciário. 8 ed. Curitiba: Alteridade Editora, 2019.

STAFFEN, Márcio Ricardo. Estado, constituição e juizados especiais federais. Rio de Janeiro: Lumen Juris, 2015.

TEIXEIRA, Anderson Vichinkeski. Ativismo judicial: nos limites entre racionalidade jurídica e decisão política. Rev. Direito GV, v. 8, n. 1, 2012, p. 37-57

VALLE, Vanice Regina Lírio do. Ativismo Jurisdicional e o Supremo Tribunal Federal - Laboratório de Análise Jurisprudencial do STF. Curitiba: Juruá Editora, 2009.

ZUFELATO, Camilo. Controle judicial de políticas públicas mediante ações coletivas e individuais. In: GRINOVER, Ada Pellegrini; WATANABE, Kazuo. O controle jurisdicional de políticas públicas. Rio de Janeiro: Forense, 2011. 